\title{
Social media and their use in learning: A comparative analysis between Australia and Malaysia from the learners' perspectives
}

\author{
Vimala Balakrishnan \\ University of Malaya, Malaysia \\ Kung Keat Teoh, Tahereh Pourshafie
Flinders University, Australia \\ Teik Kooi Liew \\ Wawasan Open University, Malaysia
}

\begin{abstract}
This study is an investigation into factors that encourage and/or inhibit the use of social media in the academic learning process between Australian and Malaysian students at higher learning institutions. Push-pull-mooring theory was used as a guide, resulting in seven independent variables (convenience, social influence, academic reasons, ease of use, social networking, barriers, and e-learning perception), and one dependent variable (teaching and learning benefit). The study included a survey of 524 respondents $\left(\mathrm{N}_{\text {Australia }}=\right.$ 214; $\mathrm{N}_{\text {Malaysia }}=310$ ). Path modeling analysis revealed three common factors between students from both countries: academic reasons, barriers, and social networking. However Malaysian students revealed a significant greater emphasis on academic reasons and barriers compared to their Australian counterparts. No significant difference was noted for social networking, suggesting that the use of social media as a means to maintain social interaction is popular regardless of cultural differences. Alternatively, significant effects were observed for convenience and e-learning perception among Australian students, while ease of use was found to have significant impact on Malaysian students. The findings suggest that cultural differences and the education system will impact the use of social media as an online learning tool.
\end{abstract}

\section{Introduction}

Murray and Waller (2007; p. 56) defined social networking websites as "virtual communities for people interested in a particular subject or just to hang-out together”. Social networking sites (SNSs) or social media provide the virtual space for people to communicate and get together, hence it is arguably one of the most appropriate avenues for students to exchange ideas and learn from each other. This particular functionality has garnered the interests of academics to promote social media as part of the teaching and learning platform. A survey by Barnes and Lescault (2011) of the 456 universities and colleges found they all employed Facebook or Twitter. While the use of social media is popular in many higher institutions, research shows this does not necessarily translate to student success. The work of Junco (2012) discovered that time spent on Facebook negatively correlated to GPA. If social media provides one of the best platforms for academic discussion and knowledge exchange, why is it not affecting students' performance positively? The answer could lie with various factors, one of which may be cultural, the other possibly behavioural.

As social media encompasses interaction and social communication, this study hypothesises that cultural influences play a significant role in the use of social media in higher education. A study by Pew Internet and American Life Project shows that 63\% of Facebook users in Australia log in daily (Huray, 2013). The numbers also tell us that the most popular site Malaysians visit is Facebook at $75.5 \%$ (Nextup.Asia, 2014). A recent study investigating motivations behind the use of Facebook also revealed approximately $54 \%$ of Malaysian students log into Facebook between two and five times daily, and about 36\% spent more than 60 minutes daily online (Balakrishnan \& Shamim, 2013). Such figures clearly indicate the popularity of Facebook both in Australia and Malaysia.

This paper provides a background literature into the use of social media in higher education and explores some possible reasons for the success and failure of its use in higher education. The methodology used to study factors affecting students' use of social media in higher education is applied with the use of surveys 
conducted in various higher education institutions in Malaysia and Australia. Resulting key factors that affect students in both countries are presented, compared and discussed.

\section{Literature review}

\section{Social media and education}

A large number of students in higher education use social media (Aydin, 2012; Karvounidis, Chimos, Bersimis, \& Douligeris, 2014; Mbatha, 2014; Roblyer, McDaniel, Webb, Herman, \& Witty, 2010; Rogers-Estable, 2014). According to a Facebook spokesperson, approximately 297,000 users in 2011 identified themselves as academics (Roblyer et al., 2010). In Australia, a vast majority of students were found to have an active Facebook account, with a significant percentage (81.9\%) having engaged with a coursework Facebook page at some stage in the semester (Irwin, Ball, \& Desbrow, 2012). The study is indicative of Facebook having the potential to promote collaborative and cooperative learning. In some ways, social media offers a more liberal and informal way of discussion (Lampe, Wohn, Vitak, Ellison, \& Wash, 2011) compared to bulletin boards or online forums, which tend to be more structured and formal. The fact that many students check their social media statuses regularly indicates that information is relayed more effectively and discussions are livelier on this platform. For example, in a study by Bosch (2009), a lecturer attested that she found social media a more effective and easy way to communicate with students. Even lecturers who were not incorporating social media formally in their courses discovered that students have found ways to engage with them via social media. A more recent study by Sobaih, Moustafa, Ghandforoush and Khan (2016) found that social media can potentially benefit teaching and learning, but is under utilised in most faculties. In fact, several studies have reported positive affordances for teaching and learning using social media (Irwin et al., 2012; Junco, 2012; Karvounidis et al., 2014; Mbatha, 2014; Sobaih et al., 2016). Despite the benefits of social media in teaching and learning, the levels of adoption for professional and teaching purposes lag behind that of personal use (Mbatha, 2014; Roblyer et al., 2010; Rogers-Estable, 2014; Veletsianos \& Kimmons, 2013).

\section{Factors affecting social media and learning}

This section explores some of the factors affecting the success and use of social media in higher education that have been identified in previous studies. The methodology, including sampling, instrument and survey design is influenced significantly by factors identified in the literature presented below.

\section{Social media and academic performance}

An initial study by Maguth, Yamaguchi and Elliot (2010) showed that students use social media for various academic activities such as research, communication, collecting evidence and so on. In spite of this, research shows that the use of social media does not translate to students' academic success. For example, Gupta and Irwin (2016) found that Facebook could distract students, especially when the learning tasks are deemed less important. A similar sentiment was shared by Junco (2012). The popularity of social media usage among students for academic activities and its relation to negative implications on academic performance implies that a vacuum exists in current knowledge about how social media is perceived and used by students and academics.

\section{Abuse of social media, public disclosure of personal information, and privacy concerns}

One of the reasons for the privacy concerns is plausibly the abuse of social media by students. Such abuses may range from cyberbullying, stalking, and infringement of privacy (Aydin, 2012). Privacy issues may result in apprehension towards the use of social media in education (Cain, 2008). For example, Manca and Ranieri (2016) found privacy to be one of the factors that inhibit the use of social media for educational purposes. On the other hand, research has shown that students perceive academics with high self-disclosure in social media as more credible (Mazer, Murphy, \& Simonds, 2009). Interestingly, the same study also found that academics who portray themselves as strict and formal in class, yet display a friendly and informal social media personality, confuse students. There are however, academics, parents, and students who believe that academics should not be deemed as friends with students, and that there should be a clear line drawn between faculty and students (Sturgeon \& Walker, 2009).

While existing research affirms that privacy concerns, cyberbullying, and public disclosure of information influence students' perceptions of the use of social media in higher education, little is known about how 
they affect people of different cultures and norms. The question remains: Do these factors influence all students generally, or are some cultures more tolerant of these factors compared to others?

\section{Social media and its effect on actual study time}

Another reason that may attribute to the lower academic performance of social media users could merely be that social media distracts them from actual study. Interviews with some academics show that many perceived time spent on social media as wasted time which could be better spent on actual study (Bosch, 2009). In addition, Janković, Nikolić, Vukonjanski and Terek (2016) found that students who were pressed for time tend to sacrifice learning time over Facebook time. Stutzman (2008) reports that most students and academics originally intended for social media to be primarily used as a communication tool. It is therefore pertinent to know if the use of social media for communication and socialisation affect students' actual study time. More importantly, if students initially intend for SNS to be used for communication, will their priorities and intention change over time as they become buried in their academic work?

\section{Social media and its perceived ease of use}

Another factor that may affect students' use of social media is the perceived ease of use of these sites. Compared to other complicated e-learning sites, social media are arguably deemed rather user friendly. The perceived ease of use of social media has been suggested as a contributing factor to its popularity for educational purposes, and contributes to group communication success as well (Special \& Li-Barber, 2012; Ractham \& Firpo, 2011). Considering that there are over 198 social media providers listed by Wikipedia (Teoh, Pourshafie, \& Balakrishnan, 2014), it is important to examine if users' experience in using social media will determine its success and popularity in higher education. However, few researches have looked at how social media's perceived ease of use affects online learning's success.

\section{Social media and cultural factors}

Cultural factors may also affect the use of social media for online learning. Many studies exist in the area of culture and its effects on learning. Some researchers reported that cultural differences between western and Asian students affect teaching philosophies, approaches and strategies (Watkins, 2000). Cultural norms affect the way students think, making it a vital influencing factor in their self-regulated learning process. For example, a study by Purdie and Hattie (1996) showed that Japanese students learn by applying more memorisation as opposed to Australian students. Similarly, Niles' (1995) study of Australian and Asian students showed that Australians are more motivated to excel by competition while Asians are motivated by their social standards and expectations.

Research shows that culture has an impact on how social media is perceived and used. A study by DeAndrea, Shaw and Levine (2010) for example, showed that culture has an impact on how users describe and represent themselves on social media sites. The same study also reported that culture influences how users express themselves and communicate on social media. Interestingly, culture was also found to be among factors that influence how online learners perceive the quality of instructions (Bentley, Tinney, \& Chia, 2005). Chen and Mashhadi (1998) also urged online instructional designers to consider culture when designing materials for online learning.

While the impact of culture on education is well documented, there is a lack of literature on studies focusing on the impact of culture on social media, particularly the use of social media in education. We conclude that a cross cultural study is essential to examine if the same set of factors are perceived differently by students with various cultural background and norms. Existing literature shows that there are several factors that potentially influence the use of social media in higher education. Some of these factors act as barriers while others act as motivators for students to use social media for learning. While research shows that the use of social media in higher education can impact academic performance, there is little research to identify these factors. In addition, while studies show that various cultures respond differently to the use of social media, there are few studies on cross cultural implications of social media use in higher education. 


\section{Methodology}

\section{Push, pull and mooring theory}

This research framework was designed around the push, pull and mooring (PPM) model and instruments were developed based on factors identified in the literature. In general, the instruments were based on the following factors: ease of use, academic reasons, social networking, e-learning perception, barriers, convenience, and social influence. In order to assess the impact of these factors, we also designed a factor called teaching and learning benefit. Table 1 (Teoh et al., 2014) provides the definitions for the factors.

Table 1

Definition of factors used in study (Teoh et al., 2014)

\begin{tabular}{ll}
\hline \multicolumn{1}{c}{ Factor } & \multicolumn{1}{c}{ Definition } \\
\hline $\begin{array}{l}\text { Convenience } \\
\text { Social influence }\end{array}$ & $\begin{array}{l}\text { Perceived ease of availability of social media for learning } \\
\text { The degree of social influence to use social media in learning } \\
\text { The degree to which the respondent perceives social media as an academic } \\
\text { tool for learning } \\
\text { Perceived degree of effortlessness in the use of the social media for } \\
\text { learning } \\
\text { The degree to which the users use social media to keep in touch with } \\
\text { his/her social group }\end{array}$ \\
$\begin{array}{l}\text { Barriers } \\
\text { e-Learning perception } \\
\text { Teaching and } \\
\text { learning benefit }\end{array}$ & $\begin{array}{l}\text { Simitations and obstacles in using social media for learning } \\
\text { Perceived academic benefits from using social media in higher education }\end{array}$ \\
\hline
\end{tabular}

The PPM theory was originally developed to study human migration. In the initial model, only push and pull factors were introduced (Lee, 1966; Moon, 1995). Later, mooring was introduced by Bogue (1969) to explain why some people opted not to migrate. Pull generally refers to motivating factors that attracts people to a country. Examples of factors that motivate human migration are economic prosperity, peace, and better education. Push refers to factors that discourage people from staying, and instead motivate them to leave their existing country. Examples of push factors may include war and famine. Finally, mooring refers to factors which influence people to stay in a country. Such factors may include family obligations, job security and age.

In general, our pull factors for students to use social media in education are convenience, zocial influence, academic reasons, ease of use, and social networking. The push factor is e-learning perception. The mooring factor in our model is barriers.

\section{Materials and methods}

A 31-item questionnaire was designed covering all the factors identified from the literature (Galy, Downey, \& Johnson, 2011; Hayashi, Chen, Ryan, \&Wu, 2008; Kim, Sohn, \& Choi, 2011). An initial pilot test involving 24 respondents were conducted. Face validity of the questionnaire was also confirmed by seeking the assistance of six university students and two academics. In general, the results of the pilot study indicated high reliability with a Cronbach’s alpha score of above 0.81 .

The questionnaire began with a brief introduction to the purpose of the study, and the definition of social media. In the current study, the students were asked to answer the questions based on their experience from using any form of social media, instead of focusing on a specific platform. However, a few statements required the researchers to be specific about the tool in question, therefore it is explicitly mentioned in the questionnaire (see Table 2 for the complete list of statements).

The questionnaire comprised of four sections. Section 1 solicited demographic data such as gender, age (ordinal), category (i.e. undergraduate or postgraduate), and the types of social media used (i.e. respondents were asked to choose at least one type from a list consisting of Facebook, YouTube, LinkedIn, Google+ etc.). Sections 2 to 4 comprised of statements related to perceptions on current elearning platforms, social media and learning, and factors that might deter the use of social media for 
learning, respectively (Table 2). These statements were measured using a 5-point Likert scale ( $1=$ strong disagreement and 5 = strong agreement). There were a total of 31 statements.

Table 2

Survey statements for Sections 2 to 4 of the questionnaire

\begin{tabular}{|c|c|c|}
\hline No & Coded items & Items \\
\hline 1 & AR1_Group_participation & $\begin{array}{l}\text { Groups and page participation in Facebook make access to learning } \\
\text { materials easier. }\end{array}$ \\
\hline 2 & AR2_SN_enhance & $\begin{array}{l}\text { Academics in my university/college use social media to enhance teaching } \\
\text { methods. }\end{array}$ \\
\hline 3 & AR3_Intellectual & Intellectuals attract my attention in social media. \\
\hline 4 & BAR1_SocNet_Conservative & I am conservative as such I do not like socialising on internet. \\
\hline 5 & BAR2_SocNet_Distraction & I enjoy working alone, social sites distract my attention. \\
\hline 6 & BAR3_SocNet_Procrastinate & I am concerned about privacy issues on social media. \\
\hline 7 & BAR4_Quit & $\begin{array}{l}\text { I've joined social sites in the past but I had to quit because it was time } \\
\text { consuming and involved more time management. }\end{array}$ \\
\hline 8 & BAR5_Lack_Motivation & $\begin{array}{l}\text { Lack of motivation from colleagues discouraged me from joining social } \\
\text { media sites. }\end{array}$ \\
\hline 9 & BAR6_Unknown_Benefits & $\begin{array}{l}\text { I do not know that I am able to use social media to enhance my academic } \\
\text { learning process. }\end{array}$ \\
\hline 10 & CON1_Communication_fast & Communication on social media platforms is much faster. \\
\hline 11 & CON2_YouTube_Materials & $\begin{array}{l}\text { When searching for a specific video/audio clip, YouTube always suggests } \\
\text { similar related video/audio clips. }\end{array}$ \\
\hline 12 & CON3_YT_simple_search & YouTube simplifies sharing of video/audio files online. \\
\hline 13 & CON4_SN_goodmedium & $\begin{array}{l}\text { Social sites are good medium for students and academics to connect and } \\
\text { communicate. }\end{array}$ \\
\hline 14 & ELP1_Elearning_Satisfaction & $\begin{array}{l}\text { I am satisfied with the current e-learning platform provided by my } \\
\text { university/college. }\end{array}$ \\
\hline 15 & ELP2_Elearning_communication & $\begin{array}{l}\text { The current e-learning platform allows me to communicate with my peers } \\
\text { and/or academics. }\end{array}$ \\
\hline 16 & ELP3_Elearn_Assist & $\begin{array}{l}\text { My peers and/or academics are easily available for academic assistance via } \\
\text { the e-learning platform. }\end{array}$ \\
\hline 17 & ELP4_Elearning_enhanceteaching & The current e-learning platform enhances my style of academic teaching. \\
\hline 18 & ELP5_Elearning_fulfilneeds & $\begin{array}{l}\text { I am able to use the e-learning platform to fulfill all my learning/teaching } \\
\text { needs. }\end{array}$ \\
\hline 19 & EoU1_Communication_easy & Communication in social media platforms is much easier \\
\hline 20 & EoU2_SN_attractvariety & $\begin{array}{l}\text { I am attracted to the variety of communication features available on social } \\
\text { media (e.g. able to upload materials, posts, send messages etc.). }\end{array}$ \\
\hline 21 & EoU3_PreferSN & $\begin{array}{l}\text { I would prefer to use social media compared to other modes (emails, phone } \\
\text { calls) as a communication medium with peers and/or academics as it is } \\
\text { simple and easy to use. }\end{array}$ \\
\hline 22 & SI1_SN_friendsinfluence & Friends and family influence the way I use social media in learning. \\
\hline 23 & SI2_SN_acainfluence & My academics influence the way I use social media in learning. \\
\hline 24 & SI3_SN_friendstaught & $\begin{array}{l}\text { Friends taught me how to access learning materials through social media } \\
\text { sites. }\end{array}$ \\
\hline 25 & SI4_SN_acataught & $\begin{array}{l}\text { My academics taught me how to access learning materials through social } \\
\text { media sites. }\end{array}$ \\
\hline 26 & SN1_SN_makenewfriends & I use social media to make new friends. \\
\hline 27 & SN2_SN_meetexperts & I use social media to meet people of the same field of study. \\
\hline 28 & TLB1_SocNet_Benefits & I am benefitting a lot (academically) through social media usage. \\
\hline 29 & TLB2_Aca_shouldjoin & I would like academics to join social media sites to assist students. \\
\hline 30 & TLB3_SN_interaction & $\begin{array}{l}\text { I believe social media can be used to improve the interaction among peers } \\
\text { and between students and academics. }\end{array}$ \\
\hline 31 & TLB4_SN_collaboration & $\begin{array}{l}\text { I believe social media can be used to improve collaboration among peers, } \\
\text { students and academics. }\end{array}$ \\
\hline
\end{tabular}


The final questionnaire was distributed to students in Malaysia and Australia. In Malaysia, the questionnaire was posted using Google docs, and the respondents were assumed to be familiar with social media platforms such as Facebook, YouTube and Twitter. The potential respondents were approached by means of emails, and Facebook, as well as word of mouth. Emails for example, were sent to randomly identified university students using their mass email accounts, obtained from their respective universities, students, and through personal contacts. The data collection was completed in approximately 6 weeks, resulting in a total of 310 respondents comprising of both undergraduate and postgraduate students.

Similarly, the Australian respondents were also assumed to be familiar with social media, as recent documented statistics show tools such as Facebook, Linkedln, and Instagram to be highly popular (Sensis, 2015). Approval and consent were obtained from the ethics committee, participating faculties, schools and academics. Visits were made to several university classroom sessions in order to hand deliver a cover letter introducing the study which assured privacy of respondents' personal data along with a respondent consent form. Two hundred and fourteen respondents participated in the study in Australia. They were undergraduate and postgraduate students from various faculties including education and the health sciences.

\section{Data analysis}

Statistical Package for the Social Sciences (SPSS) 20.0 and SmartPLS 2.0 were used for data analysis. The demographic details were analysed using descriptive statistics where partial least squares structural equation modeling (PLS-SEM) was applied to estimate and verify the research model. As the current study aims to explore the underlying factors influencing the use of social media in learning, PLS-SEM is best suited for this purpose (Hair, Christian, \& Sarstedt, 2011). Bootstrapping with 5000 re-samples was performed to obtain the statistical significance of path coefficients using a $t$-test (Hair et al., 2011). In addition, pair-wise comparisons were made to determine if there is any significant difference $(p<0.05)$ between the factors for the Malaysian and Australian samples.

\section{Results}

\section{Respondents' demographic descriptions}

There were 524 respondents $\left(\mathrm{N}_{\text {Malaysia }}=310 ; \mathrm{N}_{\text {Australia }}=214\right.$ ), with 137 males and 173 females (Malaysia), and 150 females and 64 males (Australia). The majority of the respondents in both countries fell in the age range of 18 to 20 years old, while a small percentage of them were older than 40 years of age. In both countries the majority of respondents were made up of undergraduate students. Table 3 provides these specific details.

Table 3

Demographic details of the respondents

\begin{tabular}{llcccc} 
& & \multicolumn{2}{c}{ Malaysia } & \multicolumn{2}{c}{ Australia } \\
\cline { 3 - 6 } Gender & Male & 137 & 44.1 & 64 & 29.9 \\
& Female & 173 & 55.8 & 150 & 70.1 \\
\hline Age & $18-20$ & 94 & 30.3 & 150 & 70 \\
& $21-24$ & 89 & 28.7 & 25 & 11.6 \\
& $25-30$ & 84 & 27.1 & 14 & 6.5 \\
& $31-39$ & 37 & 11.9 & 15 & 6.9 \\
& More than 40 & 6 & 1.9 & 10 & 4.6 \\
\hline Category & Undergraduate & 166 & 53.5 & 191 & 89.3 \\
& Postgraduate & 144 & 46.5 & 23 & 10.7 \\
\hline
\end{tabular}

\section{Path modeling analysis for Malaysia}

This section presents the path modeling analysis performed on the Malaysian data set. As stated previously, there were seven factors representing the PPM model (i.e. exogenous variables), namely 
academic reasons, barriers, ease of use, e-learning perception, social influence, convenience, and social networking. Teaching and learning benefit was the endogenous variable.

The factor loadings were first examined, and items lower than 0.7 were removed (Hair et al., 2011). To be specific, one item from Academic Reasons (i.e. to meet intellectuals), and three from Barriers (i.e. unaware of social media use in education, lack of motivation in using social media and I have quit using social media) were removed due to low loadings. The rest of the 27 items were retained, as detailed in Table 4.

Table 4

Cross-loadings for Malaysian data set

\begin{tabular}{|c|c|c|c|c|c|c|c|c|}
\hline Items & AR & BAR & $\mathrm{CON}$ & ELP & EOU & SI & SN & TLB \\
\hline AR1_Group_participation & 0.71 & 0.06 & -0.10 & 0.07 & 0.00 & -0.05 & 0.11 & -0.08 \\
\hline AR2_SN_enhance & 1.00 & -0.16 & 0.16 & 0.08 & 0.26 & 0.20 & 0.10 & 0.87 \\
\hline BAR1_SocNet_Conservative & -0.18 & 0.89 & -0.14 & -0.14 & -0.38 & -0.22 & -0.01 & -0.20 \\
\hline BAR2_SocNet_Distraction & -0.12 & 0.82 & -0.09 & -0.05 & -0.30 & -0.15 & -0.01 & -0.16 \\
\hline BAR3_SocNet_Procrastinate & -0.11 & 0.78 & -0.11 & -0.09 & -0.26 & -0.17 & -0.07 & -0.16 \\
\hline CON1_Communication_fast & 0.13 & -0.09 & 0.97 & 0.01 & 0.37 & 0.21 & -0.04 & 0.14 \\
\hline CON2_YouTube_Materials & 0.12 & -0.09 & 0.97 & 0.00 & 0.37 & 0.21 & -0.04 & 0.14 \\
\hline CON3_YT_simple_search & 0.13 & -0.09 & 0.97 & 0.01 & 0.37 & 0.21 & -0.04 & 0.14 \\
\hline CON4_SN_goodmedium & 0.22 & -0.21 & 0.88 & 0.10 & 0.40 & 0.23 & 0.04 & 0.22 \\
\hline ELP1_Elearning_Satisfaction & 0.06 & -0.12 & 0.04 & 0.96 & 0.18 & 0.05 & -0.06 & 0.07 \\
\hline ELP2_Elearning_communication & 0.06 & -0.12 & 0.02 & 0.85 & 0.19 & 0.06 & -0.01 & 0.04 \\
\hline ELP3_Elearn_Assist & 0.10 & -0.07 & 0.05 & 0.81 & 0.17 & 0.00 & -0.01 & 0.08 \\
\hline ELP4_Elearning_enhanceteaching & 0.04 & -0.12 & 0.01 & 0.91 & 0.13 & 0.07 & -0.04 & 0.04 \\
\hline ELP5_Elearning_fulfilneeds & 0.05 & -0.09 & 0.03 & 0.91 & 0.15 & 0.07 & -0.06 & 0.07 \\
\hline EoU1_Communication_easy & 0.26 & -0.32 & 0.42 & 0.19 & 0.85 & 0.24 & -0.01 & 0.33 \\
\hline EoU2_SN_attractvariety & 0.24 & -0.34 & 0.33 & 0.15 & 0.90 & 0.26 & 0.01 & 0.31 \\
\hline EoU3_PreferSN & 0.09 & -0.27 & 0.18 & 0.10 & 0.72 & 0.09 & 0.05 & 0.16 \\
\hline SI1_SN_friendsinfluence & 0.20 & -0.23 & 0.24 & 0.08 & 0.28 & 0.98 & 0.02 & 0.18 \\
\hline SI2_SN_acainfluence & 0.19 & -0.12 & 0.18 & -0.01 & 0.18 & 0.85 & 0.07 & 0.18 \\
\hline SI3_SN_friendstaught & 0.17 & -0.25 & 0.24 & 0.06 & 0.25 & 0.94 & 0.01 & 0.18 \\
\hline SI4_SN_acataught & 0.21 & -0.23 & 0.20 & 0.06 & 0.25 & 0.96 & 0.02 & 0.19 \\
\hline SN1_SN_makenewfriends & 0.10 & -0.03 & -0.02 & -0.03 & 0.01 & 0.03 & 0.99 & 0.07 \\
\hline SN2_SN_meetexperts & -0.01 & -0.04 & 0.03 & -0.07 & 0.06 & 0.03 & 0.81 & 0.01 \\
\hline TLB1_SocNet_Benefits & 0.62 & -0.26 & 0.20 & 0.13 & 0.44 & 0.15 & 0.05 & 0.82 \\
\hline TLB2_Aca_shouldjoin & 0.88 & -0.19 & 0.17 & 0.07 & 0.31 & 0.18 & 0.10 & 0.95 \\
\hline TLB3_SN_interaction & 0.83 & -0.19 & 0.15 & 0.05 & 0.29 & 0.19 & 0.04 & 0.97 \\
\hline TLB4_SN_collaboration & 0.84 & -0.16 & 0.14 & 0.05 & 0.26 & 0.19 & 0.04 & 0.95 \\
\hline
\end{tabular}

Note. AR: academic reasons; BAR: barriers; CON: convenience; ELP: e-learning perception; EOU: ease of use; SI: social influence; SN: social networking; TLB: teaching and learning benefit

All the constructs in this study were based on reflective multi-item scales, therefore they were assessed with regard to their reliability and validity. The results in Table 5 clearly show that the composite 
reliability (CR) values are more than 0.70 , demonstrating that all eight reflective constructs have high levels of internal consistency and reliability. Similarly, the average variance extracted (AVE) values are above the required minimum level of 0.50 , and thus the measures of the eight reflective constructs have high levels of convergent validity as well as high reliability. All Cronbach's alpha (CA) values also exceed the 0.7 threshold. The Fornell-Larcker criterion and the cross-loadings comparisons were used to check for discriminant validity. According to the Fornell-Larcker criterion (Fornell \& Larcker, 1981), the AVE of each latent construct should be higher than the construct's highest squared correlation with any other latent construct. In this vein, the square root of the AVE for each construct was compared with the correlations of all the other constructs. From Table 5, (shown in boldface in the main diagonal of both matrices), it can be observed that the square roots of AVE are always higher than the absolute correlations between constructs, hence discriminant validity is established.

Table 5

Reliability and validity measurements

\begin{tabular}{lccccccccccc}
\hline Factors & AVE & CR & CA & AR & BAR & CON & ELP & EOU & SI & SN & TLB \\
\hline AR & 0.61 & 0.73 & 0.71 & $\mathbf{0 . 7 8}$ & & & & & & & \\
BAR & 0.69 & 0.87 & 0.78 & -0.47 & $\mathbf{0 . 8 3}$ & & & & & & \\
CON & 0.90 & 0.97 & 0.96 & 0.17 & -0.14 & $\mathbf{0 . 9 5}$ & & & & & \\
ELP & 0.79 & 0.95 & 0.94 & 0.27 & -0.31 & 0.04 & $\mathbf{0 . 8 9}$ & & & & \\
EOU & 0.68 & 0.86 & 0.78 & 0.26 & -0.38 & 0.40 & 0.19 & $\mathbf{0 . 8 3}$ & & & \\
SI & 0.87 & 0.96 & 0.95 & 0.21 & -0.22 & 0.23 & 0.05 & 0.26 & $\mathbf{0 . 9 3}$ & & \\
SN & 0.67 & 0.70 & 0.75 & 0.39 & -0.03 & -0.01 & -0.04 & 0.01 & 0.03 & $\mathbf{0 . 8 2}$ & \\
TLB & 0.86 & 0.96 & 0.94 & 0.66 & -0.21 & 0.18 & 0.07 & 0.34 & 0.19 & 0.06 & $\mathbf{0 . 9 3}$
\end{tabular}

Note. AVE: average variance extracted; CR: composite reliability; CA: Cronbach's alpha; AR: academic reasons; BAR: barriers; CON: convenience; ELP: e-learning perception; EOU: ease of use; SI: social influence; SN: social networking; TLB: teaching and learning benefit

The overall path model estimation provided an $\mathrm{R}^{2}$ value of 0.76 for teaching and learning benefit (Figure 1), suggesting a very good explanatory power of the model. It can also be observed that four of the factors had significant direct effects on the teaching and learning benefit factor of using social media. Academic reasons had the strongest impact, followed by barriers, ease of use, and social networking. All these significant factors, except for barriers, impact teaching and learning benefit positively. The significant negative coefficient for barriers basically shows that the more the barriers, the lower the teaching and learning benefit. The reverse is true for academic reasons, social networking, and ease of use. Factors such as convenience, social influence, and e-learning perception were found insignificant to this particular sample of students.

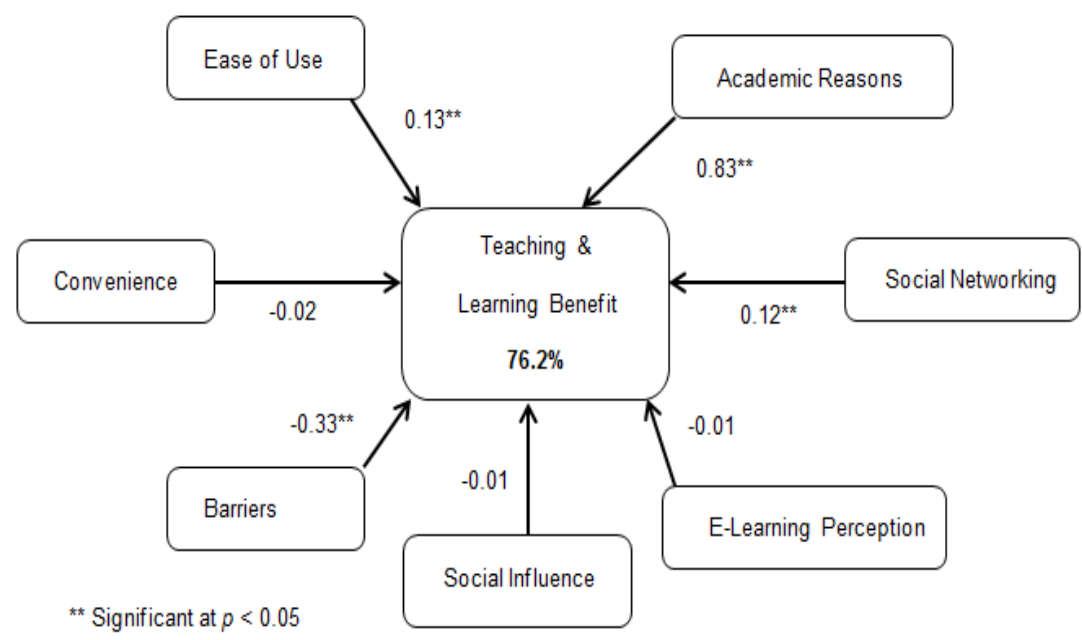

Figure 1. Path modeling analysis for Malaysian sample 


\section{Path modeling analysis for Australia}

The same model was re-tested using the sample from Australia. Table 6 shows the factor loadings for each of the construct, which are all higher than 0.7 .

Table 6

Cross-loadings for Australian data set

\begin{tabular}{|c|c|c|c|c|c|c|c|c|}
\hline Items & AR & BAR & $\mathrm{CON}$ & ELP & $\mathrm{EOU}$ & SI & $\mathrm{SN}$ & TLB \\
\hline AR1_Group_participation & 0.72 & -0.13 & 0.34 & 0.21 & 0.29 & 0.35 & 0.29 & 0.46 \\
\hline AR2_SN_enhance & 0.88 & -0.16 & 0.28 & 0.13 & 0.33 & 0.31 & 0.26 & 0.67 \\
\hline BAR1_SocNet_Conservative & -0.15 & 0.72 & -0.16 & -0.06 & -0.06 & 0.04 & -0.04 & -0.15 \\
\hline BAR2_SocNet_Distraction & -0.17 & 0.91 & -0.02 & -0.07 & -0.07 & -0.03 & -0.10 & -0.25 \\
\hline BAR3_SocNet_Procrastinate & 0.01 & 0.70 & 0.12 & 0.10 & -0.07 & 0.00 & -0.06 & -0.05 \\
\hline CON1_Communication_fast & 0.15 & -0.04 & 0.87 & 0.14 & 0.51 & 0.15 & 0.21 & 0.25 \\
\hline CON2_YouTube_Materials & 0.13 & -0.13 & 0.79 & 0.18 & 0.22 & 0.05 & 0.10 & 0.22 \\
\hline CON3_YT_simple_search & 0.21 & -0.06 & 0.79 & 0.20 & 0.26 & 0.11 & 0.15 & 0.23 \\
\hline CON4_SN_goodmedium & 0.40 & 0.03 & 0.74 & 0.12 & 0.34 & 0.37 & 0.38 & 0.36 \\
\hline ELP1_Elearning_Satisfaction & 0.04 & -0.02 & 0.13 & 0.73 & 0.05 & 0.10 & -0.04 & 0.11 \\
\hline ELP2_Elearning_communication & 0.10 & -0.03 & 0.18 & 0.77 & 0.13 & 0.15 & 0.02 & 0.18 \\
\hline ELP3_Elearn_Assist & 0.17 & -0.11 & 0.16 & 0.76 & 0.10 & 0.31 & 0.07 & 0.23 \\
\hline ELP4_Elearning_enhanceteaching & 0.19 & 0.01 & 0.21 & 0.77 & 0.17 & 0.23 & 0.07 & 0.25 \\
\hline ELP5_Elearning_fulfilneeds & 0.17 & -0.06 & 0.19 & 0.73 & 0.18 & 0.18 & 0.12 & 0.20 \\
\hline EoU1_Communication_easy & 0.21 & -0.03 & 0.52 & 0.12 & 0.80 & 0.25 & 0.37 & 0.24 \\
\hline EoU2_SN_attractvariety & 0.32 & -0.08 & 0.41 & 0.13 & 0.78 & 0.23 & 0.34 & 0.34 \\
\hline EoU3_PreferSN & 0.32 & -0.06 & 0.27 & 0.16 & 0.70 & 0.23 & 0.36 & 0.27 \\
\hline SI1_SN_friendsinfluence & 0.21 & 0.07 & 0.20 & 0.05 & 0.26 & 0.74 & 0.37 & 0.19 \\
\hline SI2_SN_acainfluence & 0.36 & 0.05 & 0.21 & 0.21 & 0.29 & 0.76 & 0.34 & 0.28 \\
\hline SI3_SN_friendstaught & 0.35 & -0.08 & 0.23 & 0.18 & 0.21 & 0.81 & 0.42 & 0.33 \\
\hline SI4_SN_acataught & 0.21 & -0.02 & 0.23 & 0.35 & 0.16 & 0.78 & 0.22 & 0.26 \\
\hline SN1_SN_makenewfriends & 0.32 & -0.12 & 0.34 & 0.03 & 0.45 & 0.38 & 0.91 & 0.34 \\
\hline SN2_SN_meetexperts & 0.29 & -0.06 & 0.32 & 0.11 & 0.40 & 0.47 & 0.92 & 0.36 \\
\hline TLB1_SocNet_Benefits & 0.59 & -0.24 & 0.37 & 0.22 & 0.33 & 0.34 & 0.32 & 0.74 \\
\hline TLB2_Aca_shouldjoin & 0.49 & -0.04 & 0.29 & 0.18 & 0.27 & 0.30 & 0.28 & 0.78 \\
\hline TLB3_SN_interaction & 0.47 & -0.19 & 0.18 & 0.16 & 0.16 & 0.14 & 0.20 & 0.71 \\
\hline TLB4_SN_collaboration & 0.53 & -0.24 & 0.38 & 0.24 & 0.34 & 0.30 & 0.31 & 0.82 \\
\hline
\end{tabular}

Note. AR: academic reasons; BAR: barriers; CON: convenience; ELP: e-learning perception; EOU: ease of use; SI: social influence; SN: social networking; TLB: teaching and learning benefit

Additionally, results also indicate that internal consistency and reliability were established considering the CR and CA values are more than 0.70 for all the constructs (see Table 7). Furthermore, the AVE is also above the required minimum level (i.e. more than 0.5 ), hence convergent validity is achieved. Finally, discriminant validity is also established as the square roots of AVE are always higher than the absolute correlations between the constructs. 
Table 7

Reliability and validity measurements

\begin{tabular}{cccccccccccc}
\hline Factors & AVE & CR & CA & AR & BAR & CON & ELP & EOU & SI & SN & TLB \\
\hline AR & 0.65 & 0.79 & 0.78 & $\mathbf{0 . 8 1}$ & & & & & & & \\
BAR & 0.50 & 0.73 & 0.74 & -0.18 & $\mathbf{0 . 7 1}$ & & & & & & \\
CON & 0.52 & 0.74 & 0.76 & 0.37 & -0.06 & $\mathbf{0 . 7 2}$ & & & & & \\
ELP & 0.54 & 0.85 & 0.79 & 0.20 & -0.06 & 0.24 & $\mathbf{0 . 7 3}$ & & & & \\
EOU & 0.58 & 0.80 & 0.74 & 0.38 & -0.08 & 0.52 & 0.18 & $\mathbf{0 . 7 6}$ & & & \\
SI & 0.52 & 0.81 & 0.70 & 0.40 & 0.00 & 0.30 & 0.28 & 0.31 & $\mathbf{0 . 7 2}$ & & \\
SN & 0.83 & 0.91 & 0.80 & 0.34 & -0.10 & 0.36 & 0.08 & 0.46 & 0.47 & $\mathbf{0 . 9 1}$ & \\
TLB & 0.54 & 0.82 & 0.71 & 0.72 & -0.25 & 0.43 & 0.28 & 0.38 & 0.38 & 0.39 & $\mathbf{0 . 7 4}$
\end{tabular}

Note. AVE: average variance extracted; CR: composite reliability; CA: Cronbach’s alpha; AR: academic reasons; BAR: barriers; CON: convenience; ELP: e-learning perception; EOU: ease of use; SI: social influence; SN: social networking; TLB: teaching and learning benefit

Figure 2 depicts the final model, with an $\mathrm{R}^{2}$ value of 0.58 for teaching and learning benefit. Although the estimation value is lesser than the Malaysian model, five of the factors were actually found to have significant direct effects on teaching and learning benefit of social media usage. Academic reasons had the strongest significant impact, followed by barriers, e-learning perception, convenience, and social networking. Similar to the Malaysian model, the negative coefficient for barriers correlates to a lower teaching and learning benefit. E-learning perception was also found to be inversely related whereby the more dissatisfied the respondents were with their current e-learning platforms the more benefits they perceive would be gained from social media as an alternative tool for learning. The remaining factors show positive path coefficients while social influence and ease of use were found to be insignificant.

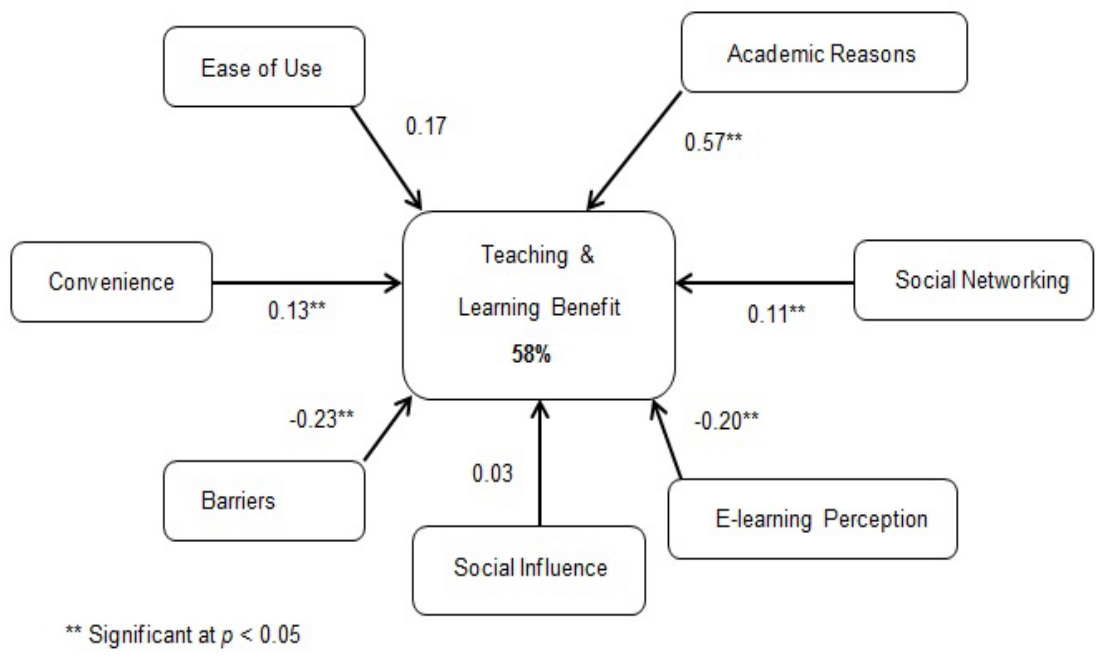

Figure 2. Path modeling analysis for Australian sample

\section{Comparisons between Australian and Malaysian samples}

Finally, the common significant factors between the models (i.e. academic reasons, barriers, and social networking) were compared to determine any difference(s) between them. Results indicate that significant differences were noted for academic reasons $(p<0.001 ; t=6.46)$ and barriers $(p=0.015 ; t=2.43)$. Looking at their respective path coefficients (Figure 1 and Figure 2), it can be observed that the Malaysian sample shows a significantly higher emphasis on academic reasons and barriers as compared to their Australian counterpart. As for the social networking factor the difference in both countries are insignificant. 


\section{Discussion}

\section{Malaysian perspective}

As reflected in the results, analysis of the reliability and validity of the eight reflective constructs by Malaysian students indicated that they no longer perceived social media merely as a platform for social interaction but also as an online tool used in the pursuit of academic knowledge. This is supported by the high $\mathrm{R}^{2}$ value of 0.76 for teaching and learning benefit along with four significant influencing factors; academic reasons, ease of use, social networking, and barriers.

From the Malaysian respondents' perspective, since barriers present itself as one of the limiting factors for teaching and learning benefit, the social media platform that would be designed to support learning must be able to minimise or overcome the barriers of using social media for learning. The education provider must ensure that the features of the social media being developed to support or enhance learning incorporate the elements of student-friendly user experience and ease of site navigation to solicit information specific to learning. The platform should support the core principles of e-learning which include high interactivity and accessibility at any time and from anywhere. The subject matter modules or content must be carefully designed to pace the learning progress of its student users. In brief, e-learning pedagogical elements of a particular module or coursework must be taken into account to achieve optimal learning experience. Thavamalar (2002) reaffirms that relevant pedagogical principles that form the basis of teaching and learning activities must be applied when developing an effective e-learning platform. This is imperative considering that Malaysian respondents placed significant emphasis on academic reasons, suggesting a positive perception towards social media as a potential tool in their learning process. Studies that reveal positive outcome from the use of social media in learning support this notion. For instance, Munoz and Towner (2009) reported that tools such as Facebook provide opportunity for academics and students to help and support each other, increasing both teacher-student and student-student interaction. Furthermore, social media have great potential to enhance learning through increased communication, networking and collaboration as opposed to the traditional classroom setting. For example, Wikis were found to be widely used in team assignments as they allow learners to collaborate in a mutually engaging environment (Miyazoe \& Anderson, 2010).

Malaysian students also identified ease of use as another deciding factor to use social media for learning. This runs parallel with the fact that the number of social media users have grown exponentially within the last decade as a result of its improved ease of use. Social media tools such as Facebook and YouTube are highly interactive, with simple layouts and mechanisms for user-friendly navigations. They are also flexible as they provide multiple means of communicating with one another. For example, Facebook users can opt to post their opinions on their walls with an option to set its audience to private, public or customised, chat with other available users and send private messages to a specific individual or groups. Such features allow users to communicate with convenience, ease and instantly. These attractive communal features probably contributed to reasons the Malaysian sample significantly emphasised on ease of use.

Finally, social networking was also found to have a significant direct effect on teaching and learning benefit among the Malaysian respondents. These results concur with numerous studies that reported the main reasons for individuals to use social media are to socialise, communicate, and maintain relationships (Escobar-Rodríguez, Carvajal-Trujillo, \& Monge-Lozano, 2014; Everson, Gundlach, \& Miller, 2013; Robyler et al., 2010). The current student generation belong to the millennial generation (i.e. Generation $\mathrm{Y}$ ), a generation known to be highly connected through social media in their daily lives.

In brief, to gain full advantage of employing social media as part of the online platform for learning among Malaysian students, the social media platform must be designed to address the four significant factors affecting teaching and learning benefit, i.e. academic reasons, ease of use, social networking, and barriers.

\section{Australian perspective}

Similarly, results also indicate that Australian students agreed strongly that social media helps in the pursuit of academic knowledge in this digital era. This is supported by the $\mathrm{R}^{2}$ value of 0.58 for teaching 
and learning benefit. It is interesting to note that besides the academic reasons, barriers, and social networking factors, convenience and e-learning perception also showed significantly their strong impacts on Australian students. Social media platforms such as YouTube, allowed its users to share material in the form of videos conveniently. Therefore, student users in particular find it easy to search, discuss and share academic materials with their peers (Moran, Seaman, \& Tinti-Kane, 2011). This may explain why Australian students find it convenient to use social media in their learning activities.

The emphasis on e-learning perception indicates the dissatisfaction Australian students have with the current e-learning platforms used in teaching and learning. Studies focusing on e-learning platforms or learning management systems (LMS) have generally found these systems to be typically academic oriented in the traditional sense where the bulk of learning still takes place through the conventional faceto-face lectures and tutorials, rendering the LMS underutilised by students (Balakrishnan, Liew, \& Pourgholaminejad, 2015). Typically these platforms are used to share or distribute academic materials such as lecture and tutorial notes, to grade assignments and projects, among others while interaction between lecturer and students are very limited. Such conventional e-learning systems tend to isolate students thus making academic satisfaction difficult to achieve especially among students whose learning experience are negatively affected by isolation (Tinto, 2000). Therefore, a social media platform that is able to facilitate interaction and collaboration with peers and experts in a student's field of study may provide a more engaging environment for learning (Junco, 2012; Kirschner \& Karspinski, 2010; Moran et al., 2011).

Finally, the fact that ease of use was not found to have any significant impact could well be a reflection of a higher computer literacy rate in Australia than in Malaysia. A strong aptitude towards computer knowledge and skills allows learners to navigate the social media sphere with ease while learning.

\section{Comparison between the Malaysian and Australian perspectives}

Though both Malaysian and Australian students use social media as an online learning tool, Malaysian students are found to place greater emphasis on the academic benefits of using social media in higher education than their Australian counterparts. Malaysian students tend to engage the social media community to share and learn the academic content of their studies while Australian students regard social media primarily as a networking site for socialising without constricting its use to the pursuit of academic knowledge. Generally, the Australians see social media as a convenient tool that creates, sustains and stimulates a wide range of social relationships.

Nevertheless, these findings reveal that students from both countries concur that social media is an important platform for information sharing and nurturing of knowledge which in turn confirms the perception by Li-Barber (2012) that social media has indeed gained its momentum as a popular tool for educational purposes. Social media will gradually transform into the basis for lifelong learning that will extend beyond the conventional learning experiences (Anderson, 2012), and in this regard all higher education institutions must tap into the potential of using social media in complementing the current conventional learning process. This study also shows that social media carries with it the potential to enhance the academic achievement of its student users and help promote collaborative learning. It also reiterates the fact that learners enjoy using social media as a complimentary tool in enriching their learning experience as reported by Veletsianos and Navarrete (2012). When social media is used as an essential learning platform it promotes the flexibility to apply varied instructional delivery formats that cater to various learning styles of the students. Furthermore, it facilitates the formation of learning communities, fostering student engagement and interactivity in the virtual learning sphere.

Social media as a technological tool will shape the future of learning and bring with it new opportunities in academia (Siemens, Gasevic, \& Dawson, 2015). Formal learning need not be constrained to the conventional set-up of a physical classroom. It can also be carried out with the help of social media technology as acceptance of it increases. Institutions need to leverage the benefits of social media to enable active learning as social media sites are proving to be the central communication space for young learners, teenagers and adults alike. In fact, with samples from both Malaysia and Australia indicating the growing relevance of using social media for academic reasons, it is highly likely that the current student generation will be motivated to adopt it as an essential learning tool. 
While both Australian and Malaysian students have regarded social media as pivotal in their learning experience, Malaysians face greater challenges in using social media for learning as explained by the Barriers factor in this study. These barriers include poor technology literacy, uneven access to internet connectivity and the geographical digital divide in terms of broadband penetration. The existence of such barriers in Malaysia and the absence of it in Australia could well be explained in the difference how technology is adopted in the educational system and the manner information technology is developed in both countries. In addition, barriers in the current study are also attributed to culture and the difference in how Malaysians and Australians view privacy issues. Malaysians are more inclined to be conservative towards online self-disclosure as compared to Australians. Research focusing on cross cultural studies also supports the same view, for example, Korean social media users were found to exhibit lower amount of personal self-disclosure than the American users (Qiu, Lin, \& Leung, 2012).

Both Australian and Malaysian participants engage actively in social media as a platform to network and socialise. Social media assists people with similar passions and goals to network either for personal, community or professional development. It is with this social incentive in mind more and more conventional education institutions are designing their online learning platform to incorporate social media features in the hopes that the strong social element will enhance the learning experience of its student users (Balakrishnan et al., 2015).

It is also interesting to note that the majority (70\%) of the Australian sample size come from the age group of 18 to 20, as opposed to the sample size from Malaysia which only accounted for 30\% from this age group. This age group is often referred to as the millennial generation, also widely known as natives of the digital era or members of the Internet generation. They were born in the digital age and interacted with digital technology from a very early age. Therefore, it is necessary to rethink conventional learning methodologies and progress towards incorporating virtual classrooms and social media as an innovative support to the education process.

\section{Conclusion, implication and future work}

This study shows that the value and use of social media can be greatly developed as an innovative and effective tool for teaching and learning. Central to this is the paradigm shift from a physically localised based learning model to a wider application of digital technology that includes social media. This would change the future of the education landscape where knowledge, skills and competencies can be acquired through a virtual learning environment.

Both the Australian and Malaysian students were found to place significant emphasis on academic reasons as motivation to use social media in learning. Since academic reasons is considered a pull factor in this study, it is imperative for the academic community to focus on this factor. Higher learning institutions in these countries should build awareness and incentivise the use of social media for academic purposes. Similarly, this study revealed other pull factors to be significant, namely, social networking, ease of use (Malaysia), and convenience (Australia). These pull factors have been previously reported by numerous studies supporting the need for social media design that is easy to use, intuitive and includes customisation features that support teaching and learning activities.

It is also important to note the importance of e-learning perception as a significant factor derived from the Australian sample. In this study, e-learning perception is a push factor indicating the Australian students are dissatisfied with their current e-learning platforms. This may also explain the motivation behind the Australian respondents' emphasis on academic reasons. In other words, students who are less satisfied with current e-learning platforms at their respective universities may opt for a better and attractive alternative that includes social media features such as real-time interactivity, video streaming and conferencing. This reaction further supports the critical need for universities to incorporate the use of social media in their teaching and learning program design.

Finally, results also indicated the influence of culture particularly for the barriers. However, interestingly students from both the countries were found to use social media for social networking despite the cultural differences. Therefore, although the communication pattern may differ between the Malaysian and Australian students, they seem to share the same motive in using social media, that is, to socialise. 
On the whole, this study shows that students from both countries are receptive to the idea of using social media for learning, as proven by good predictive powers of the models. In other words, both Australian and Malaysian students have a positive perception towards using social media to enhance teaching and learning, allow active interaction, improve communication with academics and peers, collaborate with experts, have easy access to study materials and maintain their social network at the same time. This will translate into the potential for higher learning institutions to add value and significantly improve their teaching and learning environment.

As a final remark, the findings may be used to promote the use of social media in teaching and learning, further enhancing the collaboration and communication experience between academics and students. Nevertheless, it is important to note that although observations were made on cultural differences and influencing factors, further research is needed to investigate the effects of culture in using social media for learning. Future studies are recommended to include research into several cultural dimensions such as individualism/collectivism and high/low context orientations to increase our understanding of how culture could influence social media usage in learning. It would be advantages to employ a large sample size from the millennial generation in multiple nations as a focus group of this future study. Additionally, it would also be interesting to take an in-depth look into the academics' perspectives and their responses in using social media for teaching as well.

\section{Acknowledgment}

The authors wish to extend their gratitude to all the survey respondents who made the study possible.

\section{References}

Anderson, T. (2012). Networks, Web 2.0 and the connected learner, In R. Reiser, \& J. Dempsey (Eds.), Trends and Issues in Instructional Design and Technology (pp.299-308). Boston, MA: Allyn \& Bacon.

Aydin, S. (2012). A review of research on Facebook as an educational environment. Educational technology research and development, 60(6), 1093-1106. http://dx.doi.org/10.1007/s11423-012-9260$\underline{7}$

Balakrishnan, V., Liew, T. K., \& Pourgholaminejad, S. (2015). Fun learning with Edooware: A social media enabled tool. Computers \& Education, 80, 39-47. http://dx.doi.org/10.1016/j.compedu.2014.08.008

Balakrishnan, V., \& Shamim, A. (2013) Malaysian Facebookers: Motives and addictive behaviours unravelled, Computers in Human Behavior 29(4), 1342-1349. http://dx.doi.org/10.1016/j.chb.2013.01.010

Barnes, N.G., \& Lescault, A.M. (2011) Social media soars as higher-ed experiments and reevaluates its use of new communications tools. Retrieved from http://www.prweb.com/releases/SocialMedia/Higher-Ed2011/prweb8668892.htm

Bentley, J. P., Tinney, M. V., \& Chia, B. H. (2005). Intercultural Internet-based learning: Know your audience and what it values. Educational technology research and development, 53(2), 117-127. Retrieved from http://www.jstor.org/stable/30220433

Bogue, D. J. (1969). Principles of Demography. New York, NY: John Wiley.

Boogart, M. R. V. (2006). Uncovering the social impacts of Facebook on a college campus. (Masters' dissertation). Kansas State University, Manhattan. http://dx.doi.org/10.1.1.474.1467

Cain, J. (2008). Online social networking issues within academia and pharmacy education. American Journal of Pharmaceutical Education, 72(1), 10. Retrieved from http://www.ncbi.nlm.nih.gov/pmc/articles/PMC2254235/

Chen, A.Y. \& Mashhadi, A. (1998). Asian perspectives on a culture of simulation: the challenge of virtual instruction. In T.-W. Chan, A. Collins, \& J. Lin (Eds.), Proceedings of ICCE 98 Global Education on the Net (pp. 188-197). Beijing: CHEP.

DeAndrea, D. C., Shaw, A. S., \& Levine, T. R. (2010). Online language: The role of culture in selfexpression and self-construal on Facebook. Journal of Language and Social Psychology, 29(4), 425442. http://dx.doi.org/10.1177/0261927X10377989 
Escobar-Rodríguez, T, Carvajal-Trujillo, E, \& Monge-Lozano, P. (2014). Factors that influence the perceived advantages and relevance of Facebook as a learning tool: An extension of the UTAUT. Australasian Journal of Educational Technology, 30(2), 136-151. http://dx.doi.org/10.14742/ajet.585

Everson, M., Gundlach, E., \& Miller, J. (2013). Social media and the introductory statistics course. Computers in Human Behaviour, 29(5), 69-81. http://dx.doi.org/10.1016/j.chb.2012.12.033

Fornell, C., \& Larcker, D. F. (1981). Evaluating structural equation models with unobservable variables and measurement error. Journal of Marketing Research, 18(1), 39-50. http://dx.doi.org/10.2307/3151312

Galy, E., Downey, C., \& Johnson, J. (2011). The effect of using e-learning tools in online and campusbased classrooms on student performance. Journal of Information Technology Education. 10, 209-230. Retrieved from http://iucontent.iu.edu.sa/Scholars/Information Technology/The Effect of Using E-Learning Tools in Online and Campus-based Classrooms on Student Performance.pdf

Gupta, N., \& Irwin, J. D. (2016). In-class distractions: The role of Facebook and the primary learning task. Computers in Human Behavior, 55, 1165-1178. http://dx.doi.org/10.1016/j.chb.2014.10.022

Hair, J. F., Christian M, R. \& Sarstedt, M (2011) PLS-SEM: Indeed a silver bullet. Journal of Marketing Theory and Practice, 19(2), 139-151. http://dx.doi.org/10.2753/MTP1069-6679190202

Hayashi, A., Chen, C, Ryan, T., \& Wu, J. (2008). The role of social presence and moderating role of computer self efficacy in predicting the continuance usage of e-learning systems. Journal of Information Technology Education. 15(2), 139-154. Retrieved from https://www.researchgate.net/publication/267855475_The_Role_of_Social_Presence_and_Moderatin g_Role_of_Computer_Self_Efficacy_in_Predicting_the_Continuance_Usage_of_E-Learning_Systems

Huray, A. (2013). Social media statistics Australia - May 2013. Retrieved from http://frankmedia.com.au/2013/06/03/social-media-statistics-australia-may-2013/

Irwin, C., Ball, L., \& Desbrow, B. (2012) Students’ perceptions of using Facebook as an interactive learning resource at university. Australasian Journal of Educational Technology, 28(7), 1221-1232. Retrieved from http://www.ascilite.org.au/ajet/ajet28/irwin.html

Janković, B., Nikolić, M., Vukonjanski, J., \& Terek, E. (2016). The impact of Facebook and smart phone usage on the leisure activities and college adjustment of students in Serbia. Computers in Human Behavior, 55, 354-363. http://dx.doi.org/10.1016/j.chb.2015.09.022

Junco, R. (2012). Too much face and not enough books: The relationship between multiple indices of Facebook use and academic performance. Computers in Human Behavior, 28(1), 187-198. http://dx.doi.org/10.1016/j.chb.2011.08.026

Karvounidis, T., Chimos, K., Bersimis, S., \& Douligeris, C. (2014). Evaluating Web 2.0 technologies in higher education using students' perceptions and performance. Journal of Computer Assisted Learning, 30(6), 577-596. http://dx.doi.org/10.1111/jcal.12069

Kim, Y., Sohn, D., \& Choi, S. M. (2011). Cultural difference in motivations for using social networks sites: A comparative study of American and Korean college students. Computers in Human Behaviour, 27(1), 365-372. http://dx.doi.org/10.1016/j.chb.2010.08.015

Kirschner, P. A., \& Karpinski, A. C. (2010). Facebook® and academic performance. Computers in Human Behavior, 26(6), 1237-1245. http://dx.doi.org/10.1016/j.chb.2010.03.024

Lampe, C., Wohn, D. Y., Vitak, J., Ellison, N. B., \& Wash, R. (2011). Student use of Facebook for organizing collaborative classroom activities. International Journal of Computer-Supported Collaborative Learning, 6(3), 329-347. http://dx.doi.org/10.1007/s11412-011-9115-y

Lee, E. S. (1966). A theory of migration. Demography, 3(1), 47-57.Retrieved from http://www.students.uni-mainz.de/jkissel/Skripte/Lee.pdf

Maguth, B. M., Yamaguchi, M., \& Elliott, J. (2010). Researching, producing, presenting: Students' use of technology for global advocacy in the social studies. Social Education, 74(2), 105-106. Retrieved from https://www.learntechlib.org/p/77438

Manca, S., \& Ranieri, M. (2016). Facebook and the others: Potentials and obstacles of social media for teaching in higher education. Computers \& Education, 95, 216-230. http://dx.doi.org/10.1016/j.compedu.2016.01.012

Mazer, J. P., Murphy, R. E., \& Simonds, C. J. (2009). The effects of teacher self-disclosure via Facebook on teacher credibility. Learning, Media and Technology, 34(2), 175-183. http://dx.doi.org/10.1080/17439880902923655

Mbatha, B. (2014). Global transition in higher education: From the traditional model of learning to a new socially mediated model. The International Review of Research in Open and Distance Learning, 15(3), 257-274. Retrieved from http://files.eric.ed.gov/fulltext/EJ1033097.pdf 
Miyazoe, T., \& Anderson, T. (2010). Learning outcomes and students' perceptions of online writing: Simultaneous implementation of a forum, blog, and wiki in an EFL blended learning setting. System, 38(2), 185-199. http://dx.doi.org/10.1016/j.system.2010.03.006

Moon, B. (1995). Paradigms in migration research: Exploring" moorings" as a schema. Progress in Human Geography, 19(4), 504-524. http://dx.doi.org/10.1177/030913259501900404

Moran, M., Seaman, J., \& Tinti-Kane, H. (2011). Teaching, learning, and sharing: How today's higher education faculty use social media. Babson Survey Research Group. Retrieved from http://files.eric.ed.gov/fulltext/ED535130.pdf

Munoz, C., \& Towner, T. (2009). Opening facebook: How to use facebook in the college classroom. In I. Gibson et al. (Eds.), Proceedings of Society for Information Technology \& Teacher Education International Conference 2009, (pp. 2623-2627). Chesapeake, VA: AACE.

Murray, K. E., \& Waller, R. (2007). Social networking goes abroad. International Educator, 16(3), 56-59. Retrieved from http://www.calvin.edu/academic/off-campus/instructors/ocp-facebook.pdf

Nextup.Asia. (2014). 22 facts that you must know about social media in Malaysia. Retrieved from http://www.nextupasia.com/22-facts-that-you-must-know-about-social-media-in-malaysia/

Niles, F. S. (1995). Cultural differences in learning motivation and learning strategies: A comparison of overseas and Australian students at an Australian university. International Journal of intercultural relations, 19(3), 369-385. http://dx.doi.org/10.1016/0147-1767(94)00025-S

Purdie, N., \& Hattie, J. (1996). Cultural differences in the use of strategies for self-regulated learning. American Educational Research Journal, 33(4), 845-871. http://dx.doi.org/10.3102/00028312033004845

Qiu, L., Lin, H., \& Leung, A. K.-Y. (2012). Cultural differences and switching of in-group sharing behavior between an American (Facebook) and a Chinese (Renren) social networking site. Journal of Cross-Cultural Psychology, 44(1), 106-121. http://dx.doi.org/10.1177/0022022111434597

Ractham, P., \& Firpo, D. (2011, January). Using social networking technology to enhance learning in higher education: A case study using Facebook. Paper presented at the 44th International Conference on System Sciences (HICSS), Hawaii. http://dx.doi.org/10.1109/HICSS.2011.479

Reuben, R. (2008). The use of social media in higher education for marketing and communications: A guide for professionals in higher education. EduGuru. Retrieved from http://www.fullerton.edu/technologyservices/_resources/pdfs/social-media-in-higher-education.pdf

Roblyer, M. D., McDaniel, M., Webb, M., Herman, J., \& Witty, J. V. (2010). Findings on Facebook in higher education: A comparison of college faculty and student uses and perceptions of social networking sites. The Internet and Higher Education, 13(3), 134-140. http://dx.doi.org/10.1016/j.iheduc.2010.03.002

Rogers-Estable, M. (2014). Web 2.0 use in higher education. European Journal of Open, Distance and eLearning, 17(2), 129-141. Retrieved from http://www.eurodl.org/?p=current\&article=655

Sensis. (2015). Sensis social media report May 2015: How Australian people and businesses are using social media. Retrieved from https://www.sensis.com.au/assets/PDFdirectory/Sensis_Social_Media_Report_2015.pdf

Siemens, G., Gasevic, D., \& Dawson, S. (Eds.) (2015). Preparing for the digital university: A review of the history and current state of distance, blended and online learning. MOOC Research Initiative. Retrieved from http://linkresearchlab.org/PreparingDigitalUniversity.pdf

Special, W.P. \& Li-Barber, K. T. (2012). Self-disclosure and student satisfaction with Facebook. Computers in Human Behavior, 28(2), 624-630. http://dx.doi.org/10.1016/j.chb.2011.11.008

Sobaih, A. E. E., Moustafa, M. A., Ghandforoush, P., \& Khan, M. (2016). To use or not to use? Social media in higher education in developing countries. Computers in Human Behavior, 58, 296-305. http://dx.doi.org/10.1016/j.chb.2016.01.002

Sturgeon, C. M., \& Walker, C. (2009, March). Faculty on Facebook: Confirm or deny? Paper presented at the Annual Instructional Technology Conference, Murfreesboro. Retrieved from http://eric.ed.gov/?id=ED504605

Stutzman, F.(2008). The vibrancy of online social space. In B.Rigby (Ed.), Mobilizing generation 2.0: A practical guide to using web 2.0 technologies to recruit, engage and activate youth. New York, NY: Jossey-Bass.

Teoh, K. K., Pourshafie, T., \& Balakrishnan, V. (2014, August). A gender lens perspective of the use of social network in higher education in Malaysia and Australia. Paper presented at the The International Workshop on Social Networks and its Applications on Education, Beijing. http://dx.doi.org/10.1145/2639968.2640070 
Thavamalar, G. (2002). Successful implementation of e-Learning: Pedagogical considerations. Internet and Higher Education, 4(3-4), 287 -299. http://dx.doi.org/10.1016/S1096-7516(01)00071-9

Tinto, V. (2000). Learning better together: The impact of learning communities on student success in higher education. Journal of Institutional Research, 9(1), 48-53. Retrieved from https://www.yc.edu/v5content/student-services/docs/successdocs/drtinto/LearningBetterTogether.pdf

Veletsianos, G., \& Kimmons, R. (2013). Scholars and faculty members' lived experiences in online social networks. The Internet and Higher Education, 16(1), 43-50. http://dx.doi.org/10.1016/j.iheduc.2012.01.004

Veletsianos, G., \& Navarrete, C., (2012). Online social networks as formal learning environments: learner experiences and activities. The International Review of Research in Open and Distance Learning, 13(1), 144-166. Retrieved from http://www.irrodl.org/index.php/irrodl/article/view/1078/2077

Watkins, D. (2000). Learning and teaching: A cross-cultural perspective. School Leadership \& Management, 20(2), 161-173. http://dx.doi.org/10.1080/13632430050011407

Corresponding author: Vimala Balakrishnan, vimala.balakrishnan@um.edu.my

Australasian Journal of Educational Technology @ 2017.

Please cite as: Balakrishnan, V., Teoh, K. K., Pourshafie, T., \& Liew, T. K. (2017). Social media and their use in learning: A comparative analysis between Australia and Malaysia from the learners' perspectives. Australasian Journal of Educational Technology, 33(1), 81-97. https://doi.org/10.14742/ajet.2469 